\title{
Contradicciones y paradojas del modelo de gestión urbana en el área metropolitana de Guadalajara Jalisco, México
}

\author{
Contradictions and paradoxes of the urban management \\ model in the metropolitan area of Guadalajara, Jalisco, Mexico
}

Josefina Lara [I]

\begin{abstract}
Resumen
En México el fenómeno metropolitano se identifica como un problema de política pública, lo que condujo al diseño de estructuras institucionales y mecanismos de coordinación, cuya finalidad es intentar la gestión y hacer gobernables las zonas metropolitanas del país. En estas páginas se realiza un análisis exploratorio de los problemas de gestión urbana del área metropolita de Guadalajara, donde pese a la existencia de nuevas instancias de coordinación, no se refleja una mejora sustancial en la asignación de los recursos públicos, la cooperación intermunicipal o el diseño de políticas urbanas. El objetivo es revelar las contradicciones y paradojas de un modelo donde coexisten un marco normativo de gestión urbana y una realidad caótica.
\end{abstract}

Palabras clave: gestión urbana; coordinación metropolitana; cooperación intermunicipal; área metropolitana de Guadalajara.

\begin{abstract}
In Mexico, the metropolitan phenomenon is identified as a public policy problem, which has led to the design of institutional structures and coordination mechanisms whose objective is to attempt to manage the country's metropolitan areas and make them governable. We conducted an exploratory analysis of the urban management problems of the Guadalajara metropolitan area, where, despite the existence of new coordination levels, there has been no substantial improvement in the allocation of public resources, nor in intermunicipal cooperation or in the making of urban policies. Our aim is to reveal the contradictions and paradoxes of a model in which a normative framework of urban management and a chaotic reality coexist.
\end{abstract}

Keywords: urban management; metropolitan coordination; inter-municipal cooperation; Guadalajara metropolitan area. 


\section{Introducción}

La ciudad como fenómeno alberga y expresa espacialmente múltiples dinámicas sociales, culturales, económicas y políticas; en cambio la ciudad vista como un problema, nos confronta con temas complejos inherentes a la naturaleza de los procesos sociales, las economías urbanas, las razones sociales que orientan la toma de decisiones en la ciudad, la cuestión del gobierno y las políticas, la descentralización, la participación ciudadana, los modelos de gestión y la cultura (Lefebvre, 1972; Pírez, 1995; Aguilar, 2006; Borja, 2015; Arellano, 2015).

El carácter dinámico de lo urbano en la fase del capitalismo inmobiliario-financiero (Leopoldo, 2014b) nos coloca frente a un campo social donde se teje un complejo entramado de instituciones y actores, que en el discurso consideran a la planeación como un aspecto importante, - pero que al depender de un marco constitucional que la condiciona -, deja a la planeación en el plano testimonial que hasta ahora tiene (Arellano, 2015). Tanto la planeación como la gestión urbana se encuentran en un proceso de reinvención en los países latinoamericanos. Con las reformas económicas iniciadas en la década de 1980, se buscó la construcción de aparatos estatales que facilitaran los diversos procesos de desregulación y privatización de los bienes nacionales, en favor del poder del mercado y el capital financiero; procesos que resultaron en nuevas formas de gobernar y planear el territorio. En este contexto surgen los conceptos de gobernanza y planeación participativa, como alternativas al modelo de planeación jerárquica y vertical propio del
Estado fordista en América Latina. Los modelos participativos se fundamentan en una nueva forma de gobernar las ciudades, denominada gobernanza, que concede mayor protagonismo en los procesos de diseño, planeación e implementación de políticas públicas, a actores no gubernamentales conformados en redes y asociaciones horizontales.

A la par se produce una nueva relación entre política y territorio enfocada a administrar la ocupación y uso del mismo denominada ordenamiento territorial, valorada como una política de Estado que busca la convergencia entre las políticas de desarrollo regional, espacial o territorial con el modelo de desarrollo económico (Cfr. Arellano, 2013). Sin embargo la planeación del desarrollo y las políticas territoriales como respuesta del Estado produjeron en América Latina sistemas instrumentales de planeación poco efectivos, que no terminan por construir verdaderas políticas territoriales, quedando solamente en un plano enunciativo.

Las Asociaciones Público-Privadas (APP) y la Planeación Estratégica (PE) por su parte, surgieron como instrumentos democráticos para el diseño, planeación e implementación de políticas públicas, ${ }^{1}$ destinadas a abatir las diferencias sociales históricamente imperantes en la región latinoamericana. La posibilidad de formar asociaciones con actores sociales no estatales (cámaras de comercio, organizaciones de la sociedad civil, instituciones financieras, gremios, universidades, etc.), representa un arma de doble filo, ya que como apunta Montero (2015, p. 8), "puede malograrse, por ejemplo, cuando los objetivos de los actores se alejan en demasía del interés público, o cuando existe un conflicto irreconciliable en las negociaciones 
entre actores". La planeación urbana y regional en Latinoamérica depende cada vez más de las APP, donde la falta de representación de todos los actores constituye la mayor debilidad de la herramienta, "especialmente porque puede llevar a la reproducción de las jerarquías sociales existentes 0 al diseño de agendas que perjudiquen a poblaciones vulnerables o sub-representadas" (ibid., p. 11).

En México los procesos de descentralización del periodo 1980-1990 produjeron dos cambios fundamentales: por una parte las nuevas facultades del municipio para tomar decisiones autónomas, ${ }^{2}$ que con el tiempo derivarían en una alta dependencia de las APP para el desarrollo económico de los municipios, y por otra, "la irrupción de la Nueva Economía Institucional, que ponía en evidencia la importancia de las instituciones [...], para articular y desarrollar instituciones y redes de gobernanza duraderas" (Ibíd., pp. 10-11). El punto de inflexión que representó la adopción del modelo de libre mercado, tuvo su impronta en la privatización de facto de la política nacional de desarrollo urbano. La planeación perdió totalmente su prestigio, quedando en manos del mercado inmobiliario-financiero la decisión de dónde invertir sus recursos, de forma tal, que actualmente "para el cómo, hay reglas; para el con qué, hay instrumentos, pero el dónde, deja de ser preocupación del gobierno" (Eibenschutz y Rodríguez, 2013, p. 55).

Es así que la planeación en las grandes ciudades del país (Ciudad de México, Guadalajara y Monterrey) ha quedado en manos de las fuerzas del mercado, lo que dificulta la concreción de acuerdos básicos entre los tres niveles de gobierno sobre el desarrollo de las ciudades, el trazado de infraestructuras y el sistema de movilidad vinculante. Ante este panorama resulta importante cuestionarnos: ¿han resultado efectivos los mecanismos de coordinación para estimular la cooperación intermunicipal en el área metropolitana de Guadalajara?

En estas páginas se buscará dar respuesta a la interrogante, a partir del análisis de las estructuras subyacentes en la producción del espacio urbano. El análisis enfoca el modelo de gestión urbana del Área Metropolitana de Guadalajara (AMG), con base en la visión de desarrollo contenido en los planes y programas adoptados por la metrópoli. Para tal fin se analizan los ámbitos de actuación y procesos participativos de los distintos actores, que determinan o influyen en el curso del proceso expansivo por el que atraviesa la metrópoli.

\section{El modelo de gestión del Área Metropolitana de Guadalajara}

El Área Metropolitana de Guadalajara es un sistema urbano complejo con funciones centrales en el Occidente de México, gracias a su vocación comercial y productiva, al tamaño de sus mercados, al peso de sus instituciones y a la visibilidad internacional que poco a poco va logrando. Actualmente es considerada la quinta zona metropolitana con mayor crecimiento de los países miembros de la OCDE. El AMG está compuesta por 8 unidades territoriales grandes, complejas y fusionadas que requieren nuevas formas de gobierno.

Esta difícil tarea sugiere la construcción de un gobierno metropolitano que sea capaz de articular una lógica supra e intra municipal, 
que no ponga en entredicho el equilibrio de poderes con el gobierno del Estado de Jalisco. ¿Por qué es importante un nuevo nivel de gobierno? Debido al tamaño de la población metropolitana, que se sitúa en 5.002.466 habitantes distribuidos en 61,820 ha. (IIEG, 2017), el Área Metropolitana de Guadalajara concentra el $62 \%$ de la población del Estado, y la tendencia apunta hacia la incorporación de nuevos municipios a la dinámica metropolitana, como son Zapotlanejo, Acatlán de Juárez, Tala y El Arenal. La anexión de municipios circunvecinos al AMG, se orienta hacia la conformación de una región metropolitana, donde los municipios periurbanos ${ }^{3}$ juegan un papel determinante para el futuro de la ciudad. No solo por la posibilidad de que se amplíe la superficie administrativa de la metrópoli, sino porque funcionalmente estos municipios representan una posibilidad para la expansión inmobiliaria, el crecimiento de los servicios y la diversificación de las fuentes de empleo.

Los procesos de descentralización y continua privatización del suelo rural circundante, han dado origen a un nuevo escenario territorial conformado por lugares discontinuos y distantes "que requieren de un gobierno central fuerte, con enfoque de relaciones interurbanas de competitividad y conectividad. Sin embargo, el modelo más difundido en el país es un modelo fragmentado, con presencia en el mismo territorio de un conjunto de gobiernos locales autónomos" (Carrión, 2013, p. 33) (Figura 1).

Figura 1 - El área Metropolitana de Guadalajara y los municipios periurbanos ${ }^{4}$

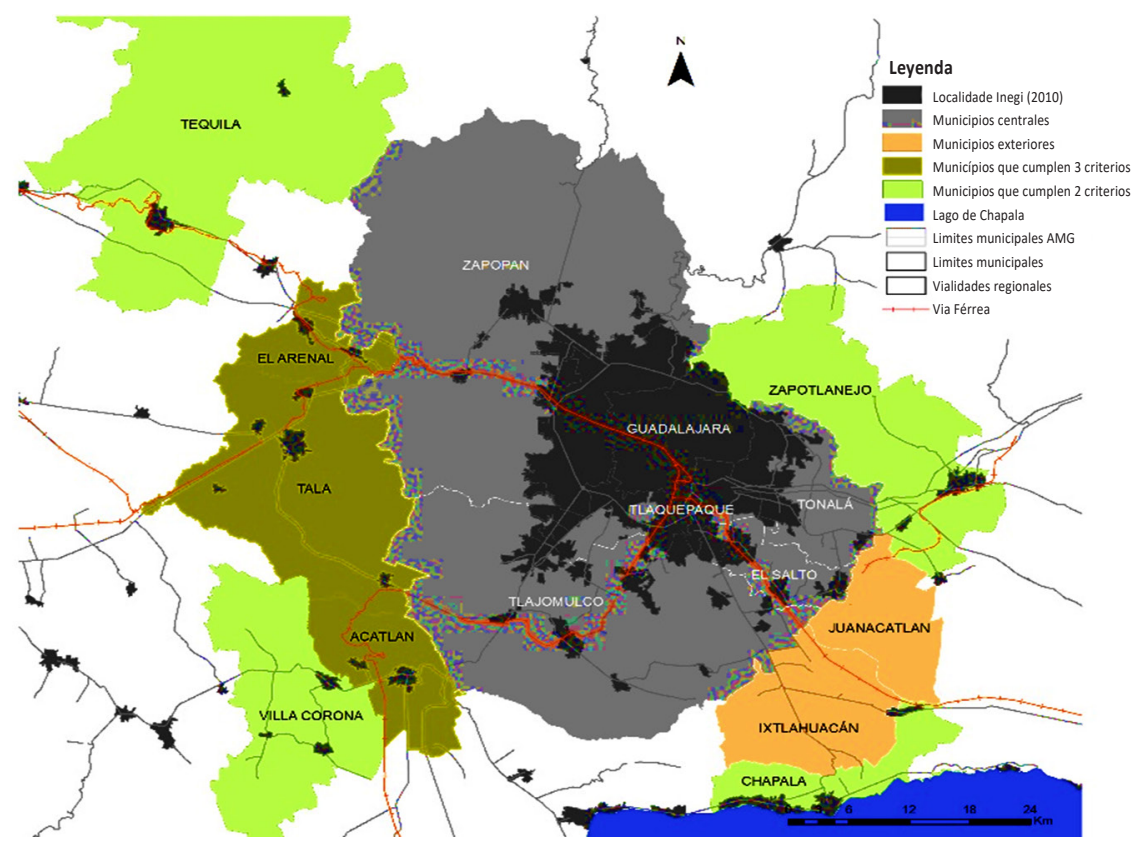

Fuente: elaboración propia con base en Imeplan, 2015. 
Este modelo induce la parcelación en la toma de decisiones de los municipios metropolitanos. Actualmente se reconoce que son las inversiones las que modelan el espacio de las ciudades y orientan el desarrollo; en el caso del Área Metropolitana de Guadalajara, las inversiones a lo largo del tiempo han seguido tendencias nacionales y de atención a situaciones de corto plazo y coyunturales, derivadas principalmente de la falta de estabilidad institucional en la administración pública. Las inversiones productivas en México están estrechamente ligadas a los periodos de gobierno, por lo tanto, carecen de continuidad y de una visión de largo plazo, especialmente en el nivel municipal.

El proceso de urbanización metropolitano responde tanto a las lógicas del racionalismo del mercado inmobiliario-financiero, como a la agresiva privatización formal e informal del suelo, que las reformas del Estado en materia agraria han consentido. El modelo de gestión urbana se manifiesta en tres ejes de cambio predominantes:

1) la tendencia hacia la flexibilización urbana por sobre el urbanismo regulador;

2) la caída en el financiamiento estatal en materia de equipamientos e infraestructura y de algunos servicios urbanos colectivos;

3) el empoderamiento de un mercado inmobiliario-financiero trasnacional, tutelado por el Estado.

De esta forma el mercado inmobiliario-financiero se ha convertido en el principal mecanismo de coordinación y gestión en la producción del suelo urbano, "ya sea a través de la privatización de las empresas públicas o por la hegemonía del capital privado en la producción de las materialidades urbanas" (Abramo, 2012, p. 36). El Mercado, al ser el principal y hegemónico mecanismo de coordinación de las decisiones de inversión, produjo una estructura híbrida fragmentada y difusa, desde el punto de vista de su morfología.

Por su parte el Estado en sus tres niveles de gobierno, se conforma como el principal agente promotor de las acciones del mercado inmobiliario. A estas dos lógicas de coordinación, se suma una tercera: "la lógica de la necesidad". Esta última reúne un conjunto de acciones individuales y colectivas que promueven la producción de la ciudad popular, con su habitual ciclo de ocupación/ autoconstrucción/auto urbanización, y finalmente, consolidación de los asentamientos populares informales (ibid., p. 36). A partir del año 2000 ha surgido una nueva variante de producción del espacio urbano, que articula la lógica del mercado formal con la de la necesidad, manifiesta espacialmente en la producción masiva de vivienda de interés social en las periferias remotas. Tanto el mercado formal como el informal de producción del suelo y la vivienda, convergen en la construcción de una metrópoli confusa que responde a sus propias lógicas económicas de funcionamiento y reproducción social. Al problema de la producción de vivienda se suman otros apremios estructurales para la metrópoli, como el problema de la movilidad y el transporte, la dotación de servicios públicos hacia lugares cada vez más alejados de la ciudad, la seguridad pública y la degradación ambiental.

Aunque en el $A M G$ se tiene una reconocida experiencia en la elaboración de instrumentos de planeación urbana, ésta "se ha convertido en rehén de los intereses del sector inmobiliario y la corrupción" (Arias y Arellano, 
2013, p. 36). Las decisiones administrativas y las acciones fuera de control de constructores y desarrolladores inmobiliarios, que influyen de manera directa en la nueva configuración de la ciudad, lograron que la planeación se convirtiera en la práctica en un conjunto de instrumentos enunciativos y nunca operativos. A nivel nacional la planeación urbana y el ordenamiento territorial han sido temas insuficientemente atendidos. Mientras que los países europeos manejan sus políticas de ordenamiento territorial dentro de un contexto, tanto interno (nacional) como externo (internacional), que permite adaptar las condiciones y objetivos específicos de sus políticas nacionales al entorno global, en México se practica una planeación racional, vertical y centralizada.

En el Estado de Jalisco durante cincuenta años (1933-1993), el gobierno estatal ejerció la rectoría en materia de legislación urbana e instrumentos de planeación urbanística; sin embargo, durante los últimos veinticinco años "se han revertido los instrumentos de planeación urbana, que hasta 1993 nos distinguía como pioneros en el ámbito nacional, [...] tendiendo en la mayoría de los casos a favorecer más el interés privado que el público y social, lo que significa el triunfo de la fuerza del mercado sobre la rectoría del Estado" (Arias, 2010, p. 461). El cambio de criterios en la aplicación de la legislación urbanística, coincide con el cambio de partido político en la gubernatura del Estado.

Durante el periodo 1995-2013, con el gobierno estatal liderado por el Partido Acción Nacional (PAN), surgieron cambios profundos en las administraciones municipales. Por primera vez se consideró una política de regionalización y la creación de instituciones públicas responsables del desarrollo urbano en el Estado. ${ }^{5}$ La política de Regionalización se estableció en una metodología para la construcción de un escenario de desarrollo orgánico-institucional, que consideraba dos variables clave: la dimensión territorial y la orientación que podría asumir el proceso de planeación y gestión regional iniciado en 1995. "La dimensión territorial se pensó idealmente en función del grado de centralización o descentralización que pudiera alcanzar el sistema de gestión pública regional, en tanto que la orientación de la planeación, permitió ponderar el tipo de organizaciones o agentes que poco a poco podrían involucrarse en el proceso de planeación y gestión regional" (Arias, 2015, p. 23).

La regionalización territorial del Estado abrió la posibilidad de una vinculación política entre los gobiernos municipales, con los actores económicos más relevantes en las regiones y con representantes de la sociedad civil. El objetivo era lograr el financiamiento compartido para obras de infraestructura, y alcanzar acciones concertadas para el desarrollo integral de los municipios. Sin embargo la trasformación institucional fracasó, lo que derivó durante el periodo 2007-2013 en la creación de la Secretaría de Planeación del Estado de Jalisco, "que privilegiaba la visión integral de largo plazo, en detrimento de la planeación regional basada en las capacidades locales" (Ibid, p. 27). Desapareció también el criterio territorial como principio ordenador y las políticas territoriales se concentraron en las posibles asociaciones inter-municipales, con miras a la conformación de nuevas zonas metropolitanas.

Por su parte la política nacional de metropolización, ${ }^{6}$ con asignación de recursos 
financieros para los municipios participantes, benefició especialmente a los municipios que conforman el AMG, lo que permitió que Zapopan y Tlajomulco se transformaran en tan solo veinte años en los nuevos polos del desarrollo metropolitano que son hoy en día. No obstante el AMG presenta un problema de gestión importante que se manifiesta en la expansión fuera de control en algunas de sus áreas, la destrucción de áreas naturales, basura, contaminación, corrupción y falta de democracia en la toma de decisiones. Aunque existe un marco normativo para la planeación urbana, los gobiernos municipales "difícilmente soltarán la atribución y competencia en materia de uso de suelo urbano. Para ello serían necesarios diversos cambios institucionales y una sociedad más activa y participativa" (Arias y Arellano, 2013, p. 37).

Actualmente el desarrollo urbano del AMG es un asunto eminentemente local organizado sobre la base de "proyecto por proyecto", o como afirma Cabrales (2008), "un modelo de ciudad por proyectos, cuyo correlato es una renuncia tácita a la planificación urbana integral". En el AMG se está gestando un proceso paralelo de expansión y reestructuración urbana, que surge de la interacción entre fuerzas económicas que están dando curso a una nueva estructura de la ciudad. Las decisiones del mercado inmobiliario-financiero para invertir en determinadas zonas de la ciudad, tiene grandes repercusiones en el sistema urbano completo, especialmente por la anexión incontrolada de suelos agrícolas a la dinámica metropolitana en áreas periféricas y por el cambio de usos del suelo y densidades edilicias del sector poniente del AMG.
En este punto valdría preguntarnos: ¿cuáles son los elementos normativos o institucionales de control de estas acciones? Muy pocos, "aunque la planeación urbana desde la década de 1980 esté contemplada en la Constitución federal y posteriormente se detalle en diversas leyes federales y estatales, y con ello se quiera creer que hay solidez institucional al ser normativa y jurídicamente reconocida, la verdad es que no es así. [...]. Esto provoca que se den al final las contradicciones y paradojas, pues hay un marco normativo de planeación urbana, y una realidad caótica" (Arias y Arellano, 2013, p. 36).

\section{Marco normativo e instancias de coordinación metropolitana}

El Sistema Estatal de Planeación para el desarrollo urbano en el Estado de Jalisco, se integra en un conjunto de planes y programas básicos, derivados y de coordinación, que ordenan y regulan el desarrollo urbano de los centros de población. El Artículo 43 de la Ley de Desarrollo Urbano del Estado de Jalisco (2010), establece un sistema de planes y programas los cuales por sus objetivos, contenidos, elementos informativos, acciones, área de aplicación y efectos jurídicos se clasifican e integran como se muestra en el Cuadro 1.

El Código Urbano del Estado de Jalisco aprobado por el Congreso Estatal, que entró en vigor a partir del $1^{\circ}$ de enero del año 2009, y que suple a la Ley de Desarrollo Urbano decretada en 1993, es un instrumento normativo que ha sido cuestionado por 
Cuadro 1 - Sistema de Planeación para el Desarrollo Urbano del Estado de Jalisco

\begin{tabular}{|l|l|}
\hline \multirow{2}{*}{ I. Planes y Programas Básicos } & $\begin{array}{l}\text { a) El Programa Estatal de Desarrollo Urbano; } \\
\text { b) El Programa Municipal de Desarrollo Urbano; } \\
\text { c) Los Planes de Desarrollo Urbano de Centros de Población; y } \\
\text { d) Los Programas de Ordenamiento Ecológico Local (POEL) previstos } \\
\text { y regulados en la legislación en materia de equilibrio ecológico y } \\
\text { protección al ambiente. }\end{array}$ \\
\hline II. Planes y Programas Derivados & $\begin{array}{l}\text { a) Los Planes Parciales de Desarrollo Urbano; y } \\
\text { b) Los Planes Parciales de Urbanización. }\end{array}$ \\
\hline III. Planes y Programas de Coordinación & $\begin{array}{l}\text { a) Los Planes Regionales de Desarrollo Urbano; } \\
\text { b) Los programas que ordenen y regulen a las zonas conurbadas } \\
\text { interestatales; } \\
\text { c) Los planes que ordenen y regulen a las zonas conurbadas } \\
\text { intermunicipales; } \\
\text { d) Los programas de ordenamiento ecológico regional, previstos } \\
\text { y regulados por la legislación en materia de equilibrio ecológico y } \\
\text { protección al ambiente; } \\
\text { e) Los planes parciales de urbanización donde se regulen y autoricen } \\
\text { acciones intermunicipales. }\end{array}$ \\
\hline
\end{tabular}

Fuente: Artículo 43, Ley de Desarrollo Urbano del Estado de Jalisco, actualizado en septiembre de 2010.

considerar que rebasa la autonomía municipal, al establecer normas específicas por encima de las atribuciones conferidas a los municipios en el Art. 115 Constitucional y en la Ley General de Asentamientos Humanos (LGAH, 1993). Por otra parte, es un documento hecho a la medida de los inversionistas privados, que coloca en primer plano los objetivos relacionados con la promoción económica y la atracción de inversiones privadas, por encima de los objetivos del desarrollo urbano sustentable, las políticas sociales y los derechos humanos. Pese a ello, es el documento que rige actualmente el desarrollo urbano en la metrópoli.
Como se observa el problema metropolitano no es la falta de normatividad, sino un problema de gestión. Por tal motivo el Área Metropolitana de Guadalajara requiere de relaciones intergubernamentales sólidas, encaminadas hacia la conformación de un gobierno metropolitano que gestione en forma eficiente la metrópoli. En el año 2011 se conformó una instancia de coordinación para el Área Metropolitana de Guadalajara, que se desprende de la reforma constitucional del año 2008 y se detalla en la Ley de Coordinación Metropolitana del Estado de Jalisco, donde se establece que la coordinación metropolitana se realizará a través de tres instancias principales: ${ }^{7}$ 
1) una instancia de coordinación política, conformada por los presidentes municipales de los ayuntamientos metropolitanos;

2) una instancia de coordinación técnica, con personalidad jurídica y patrimonio propios; y

3) una instancia consultiva y de participación ciudadana de carácter honorífico, pero con facultades suficientes para realizar tareas de evaluación y seguimiento.

Las instancias definidas como "entes intermunicipales", sustentadas en principios rectores como la autonomía municipal, la coordinación y el consenso, son las siguientes:

I) La Junta de Coordinación Metropolitana;

II) El Instituto Metropolitano de Planeación;

III) El Consejo Ciudadano Metropolitano;
IV) Las demás que establezca el estatuto orgánico del área o región metropolitana correspondiente (Art. 26, Ley de Coordinación Metropolitana del Estado de Jalisco).

Como se observa en el Esquema 1 la política de coordinación metropolitana mantiene una orientación básicamente "de abajo hacia arriba" o descentralizada, que deja en manos de los municipios la decisión final respecto a diversos asuntos urbanos de interés público. Quedan sujetos a coordinación: la planeación del desarrollo sustentable, el equilibrio ecológico, la infraestructura urbana, el suelo y reservas territoriales, las políticas habitacionales, la gestión integral del agua, la movilidad y la seguridad pública, entre otras.

Esquema 1 - Principales relaciones entre instancias de coordinación metropolitana

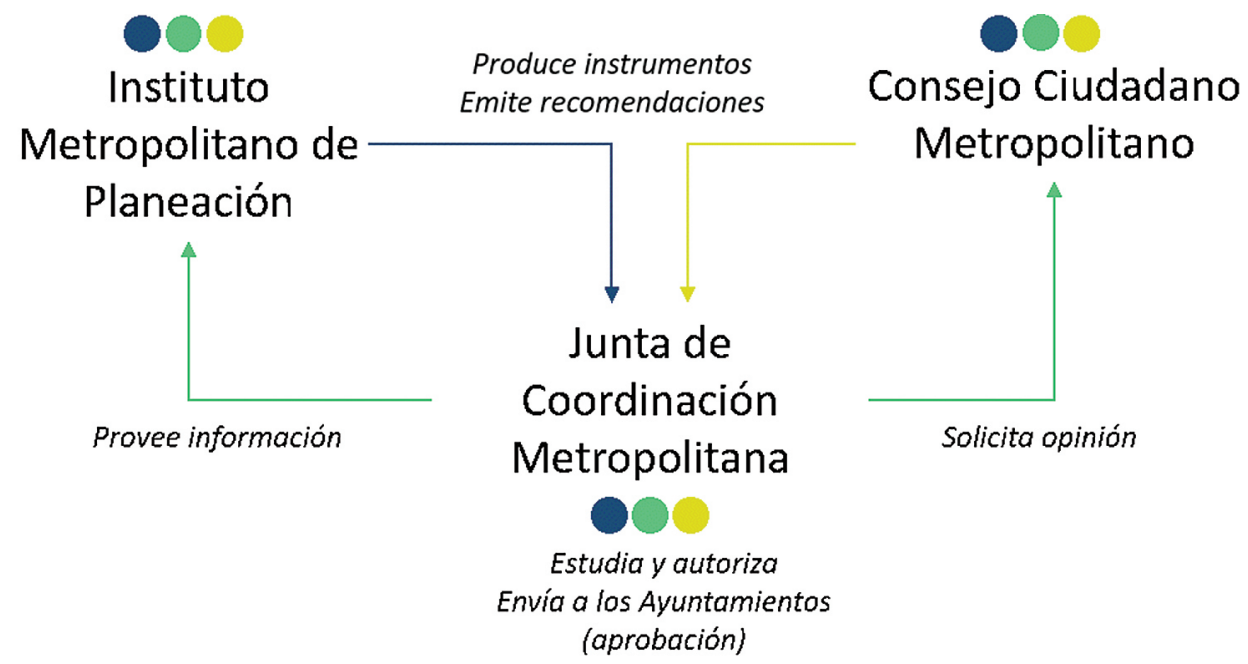

Fuente: Arellano, 2013, con base en el Artículo 106 del Código Urbano de Estado de Jalisco. 
Sin embargo esta lógica jurídica debilita el sistema de coordinación, ya que los ayuntamientos son libres de atender o no a una solicitud surgida por ejemplo de los municipios más débiles, de los contrarios a sus intereses económicos o de municipios gobernados por partidos políticos antagónicos entre sí, o al gobierno estatal. La evidencia empírica nos muestra algunas limitaciones institucionales del modelo de coordinación metropolitana, entre las que Arellano (2013) identifica las siguientes:

1) al ratificarse la preeminencia de la autoridad municipal respecto a las funciones de orden territorial y planeación del desarrollo urbano, muchos de los problemas de orden metropolitano se vuelven insalvables, (p. ej. la movilidad y la seguridad pública).

2) al concentrar en unos cuantos personajes la política de coordinación quedan fuera otros actores interesados en el desarrollo de la metrópoli, por lo que pudieran presentarse en el futuro abusos de autoridad y omisiones en el cumplimiento de las responsabilidades públicas.

3) al restarse fuerza a las estructuras centrales las autoridades estatales y federales se desvinculan automáticamente del tema del desarrollo territorial y urbano.

Es así que la gestión metropolitana no debiera ser la suma de las decisiones municipales exclusivamente, ya que en este proceso quedan fuera actores centrales necesarios para un correcto equilibrio de fuerzas. A este respecto Eibenschutz y Rodríguez sugieren que, "deben ser claras las atribuciones de unos y otros para fortalecer las decisiones centrales y buscar el camino 'de arriba abajo', que marcan las grandes estrategias del desarrollo nacional, y 'de abajo hacia arriba', que integran iniciativas locales, que permitan construir un país fuerte, donde ciertas decisiones fundamentales sigan siendo centrales, con la fuerza que les da la federación completa" (2013, pp. 55-56).

\section{El aterrizaje socio-espacial del modelo de gestión metropolitano}

Durante las últimas décadas (2000-2019) se ha implantado en México la hegemonía de un urbanismo privado que responde a los intereses del Mercado, bajo un marco normativo muy favorecedor propiciado por el mismo Estado. El nuevo marco normativo tiene su origen en tres reformas estructurales, que han permitido a la lógica del Mercado dirigir la dinámica urbana nacional:

1) la reforma al Artículo $27^{\circ}$ Constitucional (1983), que allanó teóricamente el camino a los ejidatarios para explotar, arrendar o vender su propiedad, si así lo desean;

2) la reforma al Artículo $115^{\circ}$ Constitucional (1991), que otorga a los municipios la capacidad de decidir sobre la administración y gestión sobre sus territorios;

3) la reforma institucional de los organismos nacionales de vivienda (2001): Infonavit, Fovissste y Conavi que les permite procurar su propio financiamiento privado, la introducción de una política de subsidios y créditos al sector inmobiliario y la ampliación masiva del número de derechohabientes, mediante la flexibilización en los criterios de admisión, permanencia y acceso a una vivienda (Lara y Mateos (2015, p. 177) 
Es gracias a estas reformas que a partir del año 2001 se objetiva la sujeción del Estado al poder del Mercado, es decir, se materializa la mediación subordinada del primero a la hegemonía de los capitales privados, tanto locales como regionales, extra-regionales, nacionales y aún extranjeros que operan en el país. Las reformas han provocado además desórdenes de diversa índole como:

1) la desregulación del suelo ejidal sin los elementos de control necesarios para su correcta integración a la cota de reservas urbanas;

2) la falta de instrumentos de control de las acciones de valoración del suelo;

3) el abandono de la producción de vivienda por parte del Estado mexicano;

4) la disminución de los recursos del Estado canalizados a la infraestructura, a la dotación de equipamientos y a algunos servicios colectivos;

5) la creciente presencia del mercado inmobiliario-financiero, que ocupa de lleno los espacios abandonados por el Estado.

Es de esta forma que la planificación urbana en las ciudades del país quedó bajo el control del poder del Mercado, al modificar las relaciones entre los organismos públicos de vivienda, los desarrolladores privados y el usuario demandante. A la par, la desregulación de la política habitacional obligó la readecuación del marco normativo federal en cuestiones de planeación urbanoterritorial, que como se ha visto, muestra una gran desarticulación en su aplicación.

En términos espaciales la desregulación del suelo ejidal y su posterior anexión a la cota de reservas urbanas, ha sido el gran motor del crecimiento expansivo en las ciudades mexicanas. En el caso del área metropolitana de Guadalajara las reservas se concentran principalmente en los municipios de Zapopan, Tlajomulco, El Salto y Zapotlanejo, que fue anexado por decreto en el año 2015 como el noveno municipio metropolitano, debido a la extensa cota de reservas urbanas disponibles para el futuro crecimiento de la ciudad. ${ }^{8}$

La forma fragmentada como se planea la ciudad, provoca que no exista congruencia entre los distintos Programas de Desarrollo Urbano de los municipios metropolitanos, incluidos los Programas de Ordenamiento Territorial, cuando existen, lo que deriva en acciones aisladas que solo exacerban los problemas derivados por ejemplo de la expansión desmedida de la ciudad sobre las periferias (Figura 2).

Como se observa en la Figura 2, la paradoja del modelo de planeación estriba en el hecho de que aun cuando existe suelo intraurbano disponible para el crecimiento integrado del AMG, las reservas urbanas dispuestas por los municipios metropolitanos en las periferias, duplican esta área. La huella de ciudad, entendida como la extensión del área urbana sobre el medio físico natural, excede con más de 30 mil hectáreas la superficie del espacio construido. La relación que existe entre ambas superficies, da cuenta del grado de fragmentación existente, es decir, entre más dispersos estén los espacios construidos, será mayor la cantidad del espacio abierto entre "manchas urbanas" (Imeplan, 2015, p. 64) (Tabla 1).

Inevitablemente la tendencia apunta hacia un aumento en la fragmentación del AMG. La fallida coordinación entre las dependencias de nivel estatal y municipales en el ámbito de la planeación urbana, sumada a la intensa participación del sector inmobiliario 
Figura 2 - AMG 2015*: huella de ciudad y reservas urbanas aprobadas

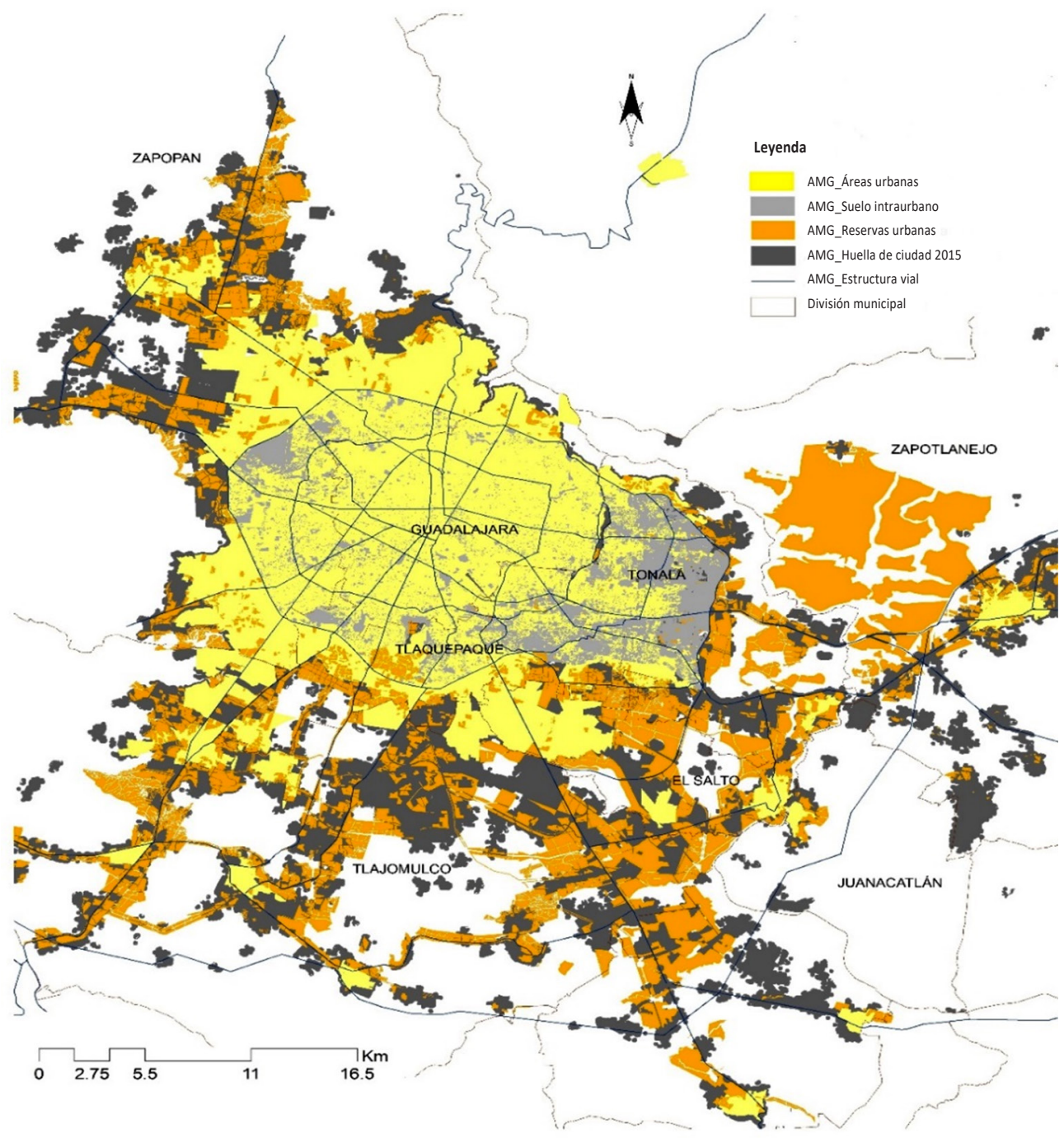

Fuente: Elaboración propia con base en Inegi, 2010 e Imeplan, 2017.

*Incluye el municipio de Zapotlanejo.

en la producción de vivienda, que opera por iniciativa de propietarios de suelo y promotores privados, se ha cristalizado en la construcción de cientos de conjuntos habitacionales en las periferias de la ciudad. Este tipo de expansión tiene repercusiones importantes para el sistema urbano completo, ya que al ampliarse las zonas con demanda de infraestructura y servicios, se reduce la capacidad económica de los municipios encargados de proveerlos. 
Tabla 1 - Situación del suelo urbano en el AMG 2015*

\begin{tabular}{l|c|c}
\multicolumn{1}{c|}{ AMG 2015 } & Polígonos & Áreas \\
\hline Superficie del espacio urbano construido & - & 61.820 ha \\
Suelo intraurbano & 20.201 & 5.988 ha \\
Reservas urbanas & 16.749 & 9.584 ha \\
Huella de Ciudad & - & 98.450 ha \\
\hline
\end{tabular}

Fuente: Imeplan 2015.

*Incluye el municipio de Zapotlanejo.

Otros impactos generados por la fragmentación urbana son los siguientes:

- aumento del grado de confrontación entre fuerzas económicas y sociales, que pugnan por la apropiación del suelo suburbano.

- incremento de la degradación ambiental en áreas valiosas para la ciudad.

- disminución de la actividad agrícola en las periferias.

- inconsistencia legal y administrativa para gestionar el territorio metropolitano.

La economía de la metrópoli depende cada vez más de los criterios a través de los cuales los capitales financieros asignan los recursos y el área donde se ejercen. Su efecto acumulativo en la toma de decisiones tiene un alto impacto en la distribución espacial de la población. Las reglas para determinar la frecuencia con que se asignan los recursos públicos son generalmente complejas y controvertidas, y aunque en muchas ocasiones se legalizan en documentos oficiales, en otras, se ocultan tras entendimientos tácitos (negociaciones) al interior de la estructura. Frente a esta circunstancia cabe preguntarnos: ¿Enfrenta la metrópoli un problema de gestión urbana?
A este respecto Knox y Pinch (2010) señalan dos elementos determinantes en la dialéctica socio-espacial de las ciudades, advirtiendo sobre el peso relativo de las instituciones de gobierno reguladoras del desarrollo urbano.

1) Las decisiones administrativas [en materia de vivienda e infraestructura], que están sujetas a las limitaciones determinadas por la economía, la política y la estructura ideológica de la ciudad;

2) Las fuerzas fuera de control en las decisiones del mercado, que ejercen una influencia importante sobre los modelos urbanos.

Es decir, las administraciones municipales dentro de la arena política deberán ser consideradas como actores importantes, pero de escasa relevancia en el contexto de la dialéctica socio-espacial, en donde los procesos económicos, sociales y políticos fijan los límites de sus actividades, mientras que los operadores profesionales del mercado inmobiliario determinan el nivel de detalle de los patrones socio-espaciales resultantes. 


\section{El problema del desarrollismo urbano en el AMG}

A partir de la reforma institucional de los organismos nacionales de vivienda del año 2001, el Estado mexicano se convirtió en el principal agente promotor de vivienda. Mediante fondos sociales específicos y créditos subsidiados controla el proceso de producción de vivienda de interés social de la mano de unos cuantos desarrolladores privados para facilitar el ciclo económico en la producción de vivienda. "En el discurso, [el Estado] indica que subsidia para favorecer a la gente de pocos recursos, en la práctica da un subsidio bruto a las empresas ${ }^{9}$ (Eibenschutz y Rodríguez, 2013, p. 55).

En México la vivienda se conforma como un sector productivo con apoyo económico del Estado, quien entiende su función como financiero de la vivienda social y aporta subsidios que vuelven más rentable el negocio inmobiliario. Por tal motivo la producción masiva de vivienda se ha convertido en el refugio más redituable para la inversión del capital financiero. De hecho, "no existe en Latinoamérica un país mejor que México para analizar las prácticas depredadoras del mercado inmobiliario. A partir del año 2001 México se ha erigido en el principal país de Latinoamérica en producción de desarrollos masivos de vivienda social, tanto por superficie como por el número de viviendas construidas" (Lara y Mateos, 2015, p. 168).

La situación de la vivienda en el Área Metropolitana de Guadalajara es solo un ejemplo del proceso especulativo del mercado inmobiliario en el país. En la Tabla 2 se revela el hecho, de que el número de viviendas producidas se ubica muy por encima de la demanda real. Mientras que en el periodo 2000-2015 el número de viviendas se incrementó en un 74,8 por ciento, la población solamente lo hizo en un 38,2 por ciento. Estas dos cifras muestran la raíz del problema del boom inmobiliario en el AMG.

Imagen 1 - Paisaje del viviendismo ${ }^{10}$ suburbano en el AMG

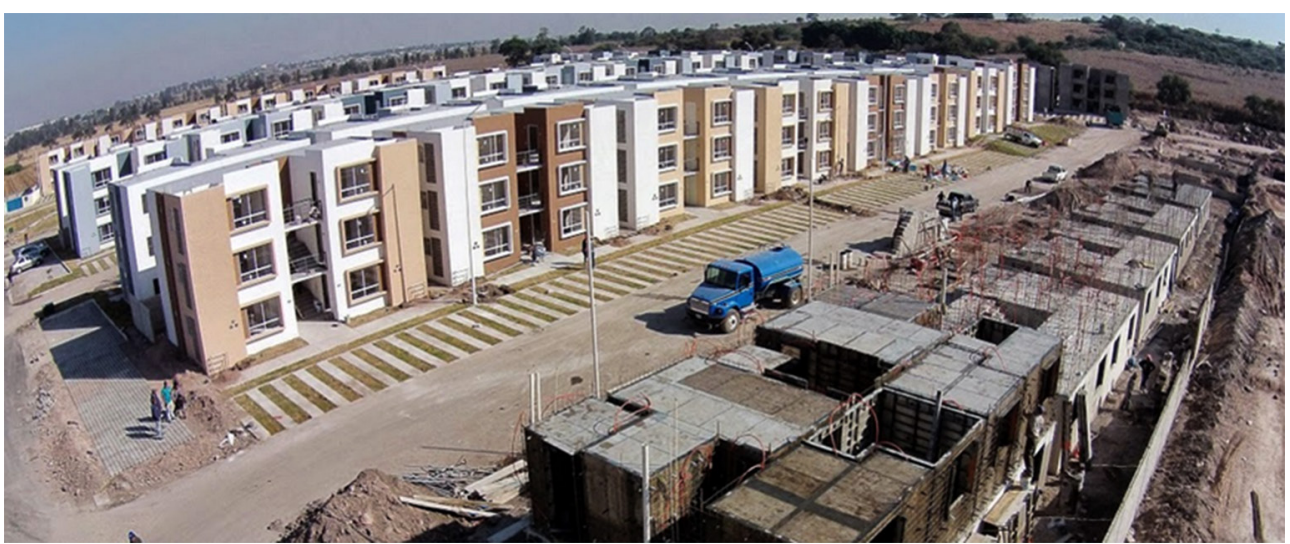

Fuente: Fotografía recuperada de Panoramio de Google Maps. 
Tabla 2 - Situación de la vivienda en el AMG 2000-2015

\begin{tabular}{l|c|c|c|c|c|c}
\cline { 2 - 6 } & \multicolumn{2}{c|}{ Vivienda } & \multicolumn{2}{c|}{ Población } & \multicolumn{2}{c}{ \% Crecimiento 2000-2015 } \\
\hline & 2000 & 2015 & 2000 & 2015 & \multicolumn{2}{c}{ \% } \\
\hline Total viviendas & 812.462 & 1.420 .803 & 3.468 .667 & 4.796 .603 & $\begin{array}{c}\text { Número } \\
\text { de viviendas }\end{array}$ & $74,87 \%$ \\
\hline $\begin{array}{l}\text { Incremento absoluto } \\
2000-2015\end{array}$ & \multicolumn{2}{|c|}{608.341 Viv. } & 1.327 .936 Hab. & Población & $38,28 \%$ \\
\hline $\begin{array}{l}\text { Superficie del espacio } \\
\text { construído }\end{array}$ & Año 2000 & 40.678 ha & Año 2015 & 61.820 ha & $\begin{array}{c}\text { Espacio } \\
\text { construído }\end{array}$ & $51,97 \%$ \\
\hline \begin{tabular}{l} 
Densidad de población \\
\hline
\end{tabular} & Año 2000 & 90,61 & Año 2015 & 77,81 & $\begin{array}{c}\text { Densidad } \\
\text { de población }\end{array}$ & $-12,80 \%$ \\
\hline
\end{tabular}

Fuente: Censos INEGI 2000 y 2010, Muestra Intercensal Inegi, 2015 e Imeplan, 2015.

La construcción de desarrollos masivos de vivienda social es el factor que más ha impactado en la metrópoli, especialmente en el aumento de la fragmentación del espacio construido. Este modelo de vivienda obedece a un número de factores coyunturales entre los que se encuentran: "la facilidad para la obtención de un crédito a los trabajadores formales avalado por el Estado; los subsidios gubernamentales a la construcción de vivienda social; el bajo precio del suelo en las periferias urbanas; la laxitud en la aplicación de normas urbanísticas y las economías de escala en la producción semi-industrial de miles de viviendas" (Lara y Mateos, 2015, pp. 179-180). La escala de operación del mercado de vivienda social, que coloca en venta entre 10 y 30 mil viviendas por desarrollo, ha propiciado el empoderamiento del sector inmobiliario-financiero, que opera al margen de las proyecciones de crecimiento esperadas para el AMG.
Actualmente la metrópoli crece de manera extensiva y dispersa por un territorio de más de 50 kilómetros de radio, mediante desarrollos de vivienda disociados del tejido urbano, lo que ha provocado el abandono de miles de viviendas, debido a las grandes distancias por recorrer entre los lugares de empleo y/o estudio y el lugar de pernocta. ${ }^{11}$ Esta situación pone en evidencia la desarticulación de los programas de ordenamiento territorial en el diseño de políticas de vivienda. Como afirma Arellano (2013, p. 11), "la importancia del territorio radica en que es un eje central de gestión institucional, que importa en las cuestiones de diseño, implementación y evaluación de políticas, así como las consideraciones de los contextos o situaciones especiales".

En suma, aunque los cambios en el modelo de gestión metropolitana pueden considerarse como un avance en cuestiones normativas, en la práctica no resuelven los 
problemas estructurales para mejorar la situación de la metrópoli, ni se orientan hacia los problemas importantes que impactan cotidianamente a la población. Problemas como el transporte y la movilidad, la seguridad pública, el aprovisionamiento continuo de agua para uso doméstico, la recolección y disposición final de basura, la contaminación y la degradación ambiental, continúan resolviéndose en el ámbito municipal, debido a que ha sido complicado establecer la coordinación entre actores políticos, económicos y sociales. La coordinación intergubernamental, ${ }^{12}$ para mejorar la función pública en relación con los problemas de la metrópoli, depende de un marco legal que limita las competencias y atribuciones de los distintos ámbitos de gobierno. Por tal motivo en ocasiones no se tienen los incentivos e instrumentos para cooperar o coordinarse de manera eficaz. Es de esta forma que los acuerdos entre actores e instituciones terminan dándose en el marco de las relaciones sociales, fuera de los esquemas formales del sistema federal.

\section{Conclusiones}

El fenómeno metropolitano en México se identifica como un problema de política pública, lo que condujo al diseño de estructuras institucionales y mecanismos de coordinación, cuyo objetivo es intentar la gestión y hacer gobernables las zonas metropolitanas del país. No obstante, estos mecanismos se encuentran en una fase inicial por lo que no han podido mostrar su eficacia en las ciudades que los han implementado.
En el área metropolitana de Guadalajara a diez años de su implementación, existen problemas de gestión y planeación urbana que inciden directamente en la forma en que la población se asienta y distribuye en el territorio. Pese a la existencia de nuevas instancias de coordinación y planeación metropolitana, no se refleja una mejora sustancial en la asignación de los recursos públicos, la cooperación intermunicipal o el diseño de políticas urbanas. Por ejemplo no existe un seguimiento al proceso de desregulación de tierras ejidales para uso urbano, lo que conduce a la destrucción de áreas naturales periféricas reguladoras del clima de la ciudad. Asimismo no se ha logrado que la toma de decisiones en cuestiones urbanas trascienda los proyectos trianuales, ceñidos a los periodos administrativos municipales. Esta circunstancia repercute negativamente en el desarrollo de la metrópoli en su conjunto; el proceso de expansión y fragmentación continua de la ciudad crea problemas de interconexión entre áreas urbanizadas y amplía las zonas con requerimiento de transporte y servicios públicos, lo que se traduce en procesos segregativos de diversa índole entre la población.

Por su extensión y el tamaño de población que ha alcanzado la metrópoli, superior a los 5 millones de habitantes, requiere de una forma de gobierno metropolitano, que sin poner en riesgo el equilibrio de poderes en el gobierno del Estado, trascienda los periodos administrativos municipales y cuente con la fuerza jurídica suficiente para hacer efectiva la coordinación, la cooperación intermunicipal y la participación ciudadana en la toma 
de decisiones que impactan la vida en la metrópoli. Esto sería posible si las relaciones intergubernamentales emergen bajo una configuración política distinta, que contribuya a facilitar las relaciones entre las nuevas instituciones y los múltiples actores sociales y económicos que participan en la construcción de la metrópoli.

\section{[I] https://orcid.org/0000-0001-7190-2368}

Universidad de Guadalajara, Centro Universitario de Ciencias Sociales y Humanidades, Doctorado en Geografía y Ordenación Territorial. Guadalajara, México.

arqjosielara@gmail.com

\section{Notas}

(1) “Una política es en doble sentido un curso de acción: es el curso de acción deliberadamente diseñado y el curso de acción efectivamente seguido" (Aguilar, 1992).

(2) La reforma al artículo 115 Constitucional de 1993, otorgó a los municipios una mayor capacidad de decisión sobre la administración y gestión de sus territorios. Con fundamento en el artículo $9^{\circ}$, Fracción I de la Ley General de Asentamientos Humanos, los municipios podrán "formular, aprobar y administrar los planes o programas municipales de desarrollo urbano, de centros de población y los demás que de éstos deriven, así como evaluar y vigilar su cumplimiento de conformidad con la legislación local" (Diario Oficial de la Federación, 21 de julio de 1993).

(3) Los municipios periurbanos o suburbanos son aquellos que se ubican fuera del área metropolitana oficialmente delimitada, pero que gozan de buena accesibilidad, por contar con vías regionales que los conectan directamente con la ciudad central; por tal motivo son receptores activos de la difusión de los fenómenos urbanos.

(4) Los municipios periurbanos o suburbanos son aquellos que se ubican fuera del área metropolitana oficialmente delimitada, pero que gozan de buena accesibilidad, por contar con vías regionales que los conectan directamente con la ciudad central; por tal motivo son receptores activos de la difusión de los fenómenos urbanos.

(5) Referido especialmente a la creación del Comité de Planeación para el Desarrollo del Estado (Coplade), instituido para promover y coadyuvar en la formulación e instrumentación del Plan Estatal de Desarrollo, tratando de compatibilizar a nivel local, los esfuerzos de los tres niveles de gobierno, relacionados con la planeación, programación, ejecución, evaluación e información del proceso de desarrollo socioeconómico de la entidad, propiciando la colaboración en estas tareas de los diversos sectores de la sociedad (Arias, 2015, p. 22). 
(6) El Grupo Interinstitucional para la Delimitación de Zonas Metropolitanas, integrado por Sedesol, Conapo e Inegi, realizó en el año 2010 la delimitación de las zonas metropolitanas del país, acción que contribuye a establecer un marco de referencia común, cuyo objetivo es fortalecer y mejorar las acciones de los tres órdenes de gobierno en la planeación y gestión del desarrollo metropolitano. Asimismo, busca contar con una base conceptual y metodológica que dé cuenta en forma exhaustiva y sistemática de la configuración territorial de las zonas metropolitanas, y proporcione criterios claros para su actualización y su caracterización comparativa a lo largo de los distintos ejercicios de delimitación (Conapo, Inegi y Sedesol, 2012. Capítulos I-IV).

(7) La Ley establece junto con el Código Urbano las reglas básicas de organización y funcionamiento de las tres instancias de coordinación metropolitana (Ley de Coordinación Metropolitana del Estado de Jalisco, 2011).

(8) Los municipios que integran originalmente el área metropolitana de Guadalajara son ocho: Guadalajara (capital de Estado), Zapopan, Tlaquepaque, Tonalá, Tlajomulco, El Salto, Juanacatlán e Ixtlahuacán de los Membrillos.

(9) Véase Sexto Informe de Gobierno de Vicente Fox Quezada (Septiembre de 2006), Recuperado de www.diputadosprd.org.mx/debate_parlamentario/articulos/LX_2006_02_37.pdf

(10) Término acuñado por René Coulomb (2010), para referirse a la construcción masiva de "vivienda sin ciudad", es decir, a la mera agregación de vivienda fuera del contexto urbano.

(11) El Instituto Nacional de Geografía y Estadística (Inegi, 2010, p. 46) define la vivienda deshabitada como aquella, que al momento del levantamiento no tiene residentes habituales, no se usa de manera temporal y está totalmente construida y disponible para ser habitada.

(12) Referido al sistema federal mexicano de tres órdenes de gobierno: municipio-estado-federación.

\section{Referencias}

ABRAMO, P. (2012). La ciudad com-fusa: mercado y producción de la estructura urbana en las grandes regiones latinoamericanas. Eure, v. 38, n. 114, pp. 35-69.

AGUILAR, A. (2006). Las grandes aglomeraciones y su periferia regional. Experiencias en Latinoamérica y España. México, Instituto de Geografía UNAM.

AGUILAR, L. F. (1992). La hechura de las políticas públicas. México, Miguel Ángel Porrúa.

ARELlANO, A. (2013). Políticas y territorio. Una valoración de la acción gubernamental. México. El Colegio de Jalisco.

(2015). Políticas, planeación y territorio. Estudios Jaliscienses. México, El Colegio de Jalisco.

ARIAS, C. (2010). Evolución de la legislación urbanística e instrumentos de planificación en Jalisco y Guadalajara de 1933 a1995 y hasta la actualidad. México, Investigaciones Jurídicas, UNAM.

ARIAS, R. (2015). “Regionalización en Jalisco: de la planeación a la gobernanza”. In: ARELLANO, A. Políticas, planeación y territorio. Estudios Jaliscienses. México, El Colegio de Jalisco. 
ARIAS, R. y ARELLANO, A. (2013). “EI Área Metropolitana de Guadalajara: travesía urbana, política y gestión metropolitana”. In: ARELLANO, A. y ORTíZ, I. (coords.) Coordinación y gestión metropolitana en Jalisco. México.

BORJA, J. (2015). La Ciudad Posible. Guía para la actuación urbana. Buenos Aires, Café de las Ciudades.

CABRALES, L. F. (2008). Guadalajara, una ciudad que se plantea cómo convertir habitantes en ciudadanos. Diario El Cronista. Buenos Aires, octubre 2, pp. 2-3.

CÁMARA DE DIPUTADOS LX LEGISLATURA (2006). Glosa del Sexto informe de gobierno del Presidente de los Estados Unidos Mexicanos Vicente Fox Quezada. Disponible en: www.diputadosprd.org. mx/debate_parlamentario/articulos/LX_2006_02_37.pdf. Acceso en: 14 diciembre 2015.

CARRIÓN, F. (2013). "El desafío político del gobierno en la ciudad metropolitana en América Latina". In: IRACHETA, A. (coord.). Reflexiones sobre política urbana. México, El Colegio Mexiquense, A.C.

CONAPO, INEGI y SEDESOL (2012). Delimitación de las zonas metropolitanas de México. Disponible en: http://www.conapo.gob.mx/es/CONAPO/Zonas_metropolitanas_2010. Acceso en: 17 abril 2019.

COULOMB, R. (2010). "Evolución reciente y situación actual del derecho a la vivienda". In: GARZA, G. y SCHTEINGART, M. (coords.). Los grandes problemas de México. México D.F., El Colegio de México.

EIBENSCHUTZ, R. y RODRÍGUEZ, R. (2013). “Globalización, desarrollo y ciudades. ¿Veinticinco años de política urbana en México?”. In: IRACHETA, A. (coord.). Reflexiones sobre política urbana. México, El Colegio Mexiquense, A.C.

IIEG - INSTITUTO DE INFORMACIÓN ESTADÍSTICA Y GEOGRÁFICA (2017). Estrategos, Revista Digital. Disponible en: https://iieg.gob.mx/strategos/alcanza-area-metropolitana-de-guadalajara-los-5millones-de-habitantes/. Acceso en: 12 marzo 2018.

IMEPLAN-INSTITUTO METROPOLITANO DE PLANEACIÓN DELÁREAMETROPOLITANADE GUADALAJARA (2015). Área Metropolitana de Guadalajara. Expansión Urbana, análisis y prospectiva: 19792045. Guadalajara, Editoriales e Industrias Creativas de México.

(2017).Open Data. Disponible en: http://datamx.io/organization/imeplanamg. Acceso en: 22 marzo 2017.

INEGI - INSTITUTO NACIONAL DE ESTADÍSTICA Y GEOGRAFÍA (2010). Censos de Población y Vivienda 1980, 1990, 2000 Y 2010. Disponible en: http://www.inegi.org.mx/est/contenidos/proyectos/ ccpv/default.aspx. Acceso en: 4 octubre 2012.

(2015). Principales Resultados de la Encuesta Intercensal 2015: Estados Unidos Mexicanos. Disponible en: http://www.inegi.org.mx/. Acceso en: 12 abril 2017

(2016). Inventario Nacional de Vivienda. Disponible en: http://www.beta.inegi.org.mx/app/ mapa/inv/. Acceso en: 25 febrero 2017.

KNOX, P. y PINCH, S. (2010). Urban social geography: an introduction. Edinburgh/England, Pearson Education Limited.

LARA, J. y MATEOS, P. (2015). "La fragmentación socioespacial del viviendismo: neoliberalismo y desarrollos masivos de vivienda social en la periferia remota de Guadalajara". In: AGUILAR, A. y ESCAMILLA, I. (coords.). Segregación urbana y espacios de exclusión. Ejemplos de México y América Latina. México, Porrúa Editores. 
LEFEBVRE, H. (1972). La revolución urbana. Madrid, Alianza Editorial.

LEOPOLDO, E. (2014). A Metropolização como negócio: conceitos e determinações emergentes do processo de transição da urbanização à metropolização. In: CONGRESO IBEROAMERICANO DE ESTUDIOS TERRITORIALES Y AMBIENTALES. Anais... São Paulo.

LEY DE COORDINACIÓN METROPOLITANA DEL ESTADO DE JALISCO (2011). Disponible en: http:// congresoweb.congresojal.gob.mx/Servicios/sistemas/SIP/.../Decreto\%2023486.pdf. Acceso en: 3 julio 2016.

LEY DE DESARROLLO URBANO DEL ESTADO DE JALISCO (2010). Disponible en: https://info.jalisco.gob. $\mathrm{mx} / \mathrm{sites} /$ default/files/leyes/Ley_de_Desarrollo_Urbano_del_Estado_de_Jalisco_0.pdf. Acceso en: 26 enero 2019.

LEY GENERAL DE ASENTAMIENTOS HUMANOS (1993). Disponible en: http://www.senado.gob.mx/ comisiones/desarrollo_social/docs/marco/Ley_GAH.pdf. Acceso en: 17 marzo 2018.

MONTERO, S. (2015). “Gobernanza y planeación regional en América Latina”. In: ARELLANO, A. Políticas, planeación y territorio. Estudios Jaliscienses. México, El Colegio de Jalisco.

PÍREZ, P. (1995). Actores Sociales y Gestión de la Ciudad. Ciudades RNIU v. 28, p. 8. México.

Texto recebido em 15/jun/2019

Texto aprovado em 11/jul/2019 